Elsevier

TOXLett. 1342

\title{
CARBON TETRACHLORIDE DEPRESSES HEPATIC PHOSPHOLIPID SYNTHESIS IN RATS
}

(Mitochondrial membranes; hepatotoxicity; oxidative phosphorylation)

\begin{abstract}
ANN MARIE W. GEBHART and MICHAEL J. BRABEC*
Department of Pharmacology, *Department of Environmental and Industrial Health, Toxicology Program, The University of Michigan, Ann Arbor, MII 48109-2029 (U.S.A.)
\end{abstract}

(Received April 18th, 1984)

(Accepted August 27th, 1984)

\section{SUMMARY}

$40 \mathrm{~h}$ after an acute dose of $\mathrm{CCl}_{4}(11.3 \mathrm{mmol} / \mathrm{kg})$, the incorporation of $\left[1-{ }^{3} \mathrm{H}\right]$ ethanolamine into rat hepatic microsomal phospholipids was inhibited to $70 \%$ of control. Incorporation into phospholipids of the inner and outer mitochondrial membranes was 30-35\% of control. Rates of incorporation were equal to or above normal rates in all membranes $65 \mathrm{~h}$ after dosage. The activity of methyltransferase in microsomal fractions isolated from rats 10 to $66 \mathrm{~h}$ after dosage was depressed. These data suggest that the alteration of mitochondrial phospholipids that parallels mitochondrial dysfunction after acute $\mathrm{CCl}_{4}$ dosage could be attributed to a $\mathrm{CCl}_{4}$-induced inhibition of the microsomal phospholipid biosynthetic pathways.

\section{INTRODUCTION}

Mitochondria isolated from rat liver display inhibited rates of respiration and oxidative phosphorylation after an acute dose of $\mathrm{CCl}_{4}[1,2]$. The relative concentrations of phospholipids in the microsomal $[3,4]$ and both the inner and outer mitochondrial membranes [5] are altered after $\mathrm{CCl}_{4}$ intoxication. The phospholipid changes in the microsomes precede those in the mitochondrial membranes [5]. The major phospholipids of the mitochondria, PC and PE, are synthesized by enzymes

*To whom correspondence should be addressed.

Abbreviations: PC, phosphatidylcholine; PD, phosphatidyldimethylethanolamine; PE, phosphatidylethanolamine; TLC, thin-layer chromatography. 
in the endoplasmic reticulum $[6,7]$ and are transferred to the mitochondria by, as yet, poorly defined mechanisms $[8,9]$. Since a profound inhibition of many microsomal enzymes, e.g. glucose-6-phosphatase [10], cytochrome P-450 [11], and the Ca-dependent ATPase [12], occurs during the early stages of $\mathrm{CCl}_{4}$ intoxication, we hypothesized that inhibition of microsomal phospholipid biosynthesis by $\mathrm{CCl}_{4}$ alters the mitochondrial phospholipid content. The disturbance of normal mitochondrial membrane phospholipid composition could inhibit the activity of the membrane-bound proteins of oxidative phosphorylation, inducing the characteristic lesions of the $\mathrm{CCl}_{4}$-poisoned hepatic mitochondria. The hypothesis was tested in rats by: (1) determining the in vivo rate of incorporation of $\left[1{ }^{3} \mathrm{H}\right]$ ethanolamine into the $\mathrm{PE}$ and $\mathrm{PC}$ fractions of microsomal and mitochondrial membranes at 40,65 and $165 \mathrm{~h}$ after $\mathrm{CCl}_{4}$, and (2) measuring the rate of methylation of $\mathrm{PE}$ to $\mathrm{PC}$ by microsomal enzymes isolated from rat liver $10,20,40$ and $65 \mathrm{~h}$ after an acute dose of $\mathrm{CCl}_{4}$. The periods correspond to the onset, maximum development, and early resolution of mitochondrial damage after this dose $(11.3 \mathrm{mmol} / \mathrm{kg})$ of $\mathrm{CCl}_{4}[1,13]$.

\section{METHODS}

\section{Animals and treatment}

Male Sprague-Dawley rats (Charles River, Portage, MI) were housed in pairs in wire-mesh-bottom cages and maintained on a diet of commercial rat chow (Purina Rat Chow, Ralston-Purina, St. Louis, MO) and water ad lib. Rats were 7-8 weeks old (190-250 g) and fasted overnight prior to killing. Animal quarters were kept on a 12 -h light/dark cycle and at a constant temperature $\left(22^{\circ} \mathrm{C}\right) . \mathrm{CCl}_{4}$ was administered intraperitoneally (i.p.) without a carrier at $1.1 \mathrm{ml} / \mathrm{kg}(11.3 \mathrm{mmol} / \mathrm{kg})$ body weight. [1- $\left.{ }^{3} \mathrm{H}\right]$ Ethanolamine $\mathrm{HCl}$ (Amersham, Arlington Heights, IL; $2-10 \mathrm{Ci} / \mathrm{mmol}$ ) was administered i.p. at a dose of $20 \mu \mathrm{Ci}$ per rat.

\section{Preparation of membrane fractions}

Rats were killed by decapitation and their livers removed. Livers from 2-10 rats were pooled and minced in ice-cold isolation media $(0.25 \mathrm{M}$ sucrose, $10 \mathrm{mM}$ Tris, $10 \mathrm{mM} \mathrm{KCl}$ and $1 \mathrm{mM}$ EDTA, $\mathrm{pH}$ 7.2). After homogenization, microsomal and mitochondrial subcellular fractions were prepared as previously reported [14] with the addition of a $15000 \times g \times 20$ min centrifugation of the post-mitochondrial supernatant fraction. This pellet contained both light mitochondria and heavy microsomes and was discarded to optimize membrane purity in the final preparation.

Inner and outer mitochondrial membrane fractions were prepared by the French press method of Decker and Greenawalt [15] with modifications as follows: the first $12000 \times g$ supernatant fraction containing broken outer membrane fragments was further purified by centrifugation at $27000 \times g$ for $10 \mathrm{~min}$, which removed fragments of damaged mitochondria, and by a discontinuous sucrose gradient at $77000 \times g$ for $90 \mathrm{~min}$, to obtain the pellet of outer membrane fragments which was then resuspended in isolation media. Protein was determined by the biuret method [16]. 


\section{Enzyme assays}

Membrane purity was assessed by the following marker enzyme assays: monoamine oxidase for the outer mitochondrial membrane [17], cytochrome $c$ oxidase for the inner mitochondrial membrane [18], and NADPH cytochrome $c$ reductase for the microsomal membrane [19].

The activity of PD methyltransferase was determined by the in vitro incorporation of $S$-[methyl- $\left.{ }^{3} \mathrm{H}\right]$ adenosylmethionine (New England Nuclear, Boston, MA; 5-15 Ci/mmol) into microsomal membrane phospholipids [20]. Dipalmitoyl PD (1.75 $\mathrm{mM}$, dissolved in methanol), served as a substrate for the final step in the Bremer-Greenberg pathway for PC synthesis [21].

The entire 3-step methyltransferase pathway was assayed following the same procedure as above with these modifications: sodium dcoxycholate was reduced to 0.9 $\mathrm{mM}$, and $2 \mathrm{mg}$ PC was included as an emulsifier. PD was omitted. The rate-limiting step of this pathway is considered to be the first methyl group addition [20, 21].

\section{Phospholipid separation and quantitation}

Phospholipids were extracted from microsomal and inner and outer mitochondrial membrane fractions by modification of the method of Folch et al. [22]. After the addition of chloroform-methanol (2:1), samples were shaken for $3 \mathrm{~min}$ in a $50^{\circ} \mathrm{C}$ water bath and then for $20 \mathrm{~min}$ at room temperature. More chloroform-methanol (2:1) and $0.4 \mathrm{M} \mathrm{KCl}$ were added to each tube. The aqueous phase was separated from the chloroform phase by centrifugation and the latter was pipetted into a clean test tube, evaporated to dryness, and frozen under nitrogen or immediately assayed.

The extracted phospholipids were separated by two-dimensional TLC on Silica Gel G plates (Eastman Kodak, Rochester, NY), and compared to phospholipid standards (Applied Science, Ann Arbor, MI; Sigma Chemical Co., St. Louis, MO). The solvent systems were chloroform-methanol-water-ammonia (70:30:3:2) and chloroform-methanol-water $(65: 35: 5)$ for the first and second directions, respectively [23]. Spots were visualized with iodine vapour and then scraped into small acid-washed flasks for determination of phosphate content [24].

\section{In vivo synthesis of phospholipids}

The synthesis of $\mathrm{PE}$ and $\mathrm{PC}$ in $\mathrm{CCl}_{4}$-exposed rats was examined by measuring the incorporation of $\left[1-{ }^{3} \mathrm{H}\right]$ ethanolamine into phospholipids of microsomal and mitochondrial membranes. Phospholipids were separated by TLC and initially all spots were scraped and counted. Only those spots previously identified as PE and PC contained any label.

Two control and two $40-\mathrm{h} \mathrm{CCl}_{4}$ animals were injected with $20 \mu \mathrm{Ci}\left[1-{ }^{3} \mathrm{H}\right]$ ethanolamine at 1, 2 and $3 \mathrm{~h}$ prior to killing to determine the time of maximum label incorporation in the microsomal and mitochondrial membrane phospholipids. In the microsomal phospholipids the greatest amount of label was found $2 \mathrm{~h}$ after dosing 
TABLE I

[ ${ }^{3}$ H]ETHANOLAMINE INCORPORATION IN CONTROL AND $\mathrm{CCl}_{4}$-TREATED RAT LIVER MICROSOMAL AND MITOCHONDRIAL MEMBRANE FRACTIONS

Rats were injected with $11.3 \mathrm{mmol} \mathrm{CCl} / \mathrm{kg}$, i.p. and killed $40 \mathrm{~h}$ later. $20 \mu \mathrm{Ci}\left[1-{ }^{3} \mathrm{H}\right]$ ethanolamine was injected i.p. 1, 2 or $3 \mathrm{~h}$ before killing. Fractions were prepared and assayed as described in METHODS. All values are averages of 2 rats per time point.

\begin{tabular}{llll}
\hline Membrane fraction & \multicolumn{2}{l}{$\begin{array}{l}\text { Time after } \\
{\left[{ }^{3} \mathrm{H}\right] \text { ethanolamine }(\mathrm{h})}\end{array}$} & \multicolumn{2}{l}{ Radioactivity (cpm/mg protein) } \\
\cline { 3 - 4 } & 1 & 4531 & $\mathrm{CCl}_{4}$ \\
\hline Microsomal & 2 & 5059 & 1131 \\
& 3 & 4036 & 2931 \\
Mitochondrial & 1 & 886 & 1998 \\
& 2 & 1252 & 304 \\
& 3 & 1418 & 872 \\
\hline
\end{tabular}

in both control and $40-\mathrm{h} \mathrm{CCl} 4$ animals (Table I). The difference in label incorporation into mitochondrial membranes between the 2- and 3-h time points was small. Therefore, in all further experiments the specific radioactivities of $\mathrm{PC}$ and $\mathrm{PE}$ were determined after extraction of the lipids from animals killed $2 \mathrm{~h}$ after receiving the $\left[1-{ }^{3} \mathrm{H}\right]$ ethanolamine. Considerably less label $(25-70 \%)$ was present in all $\mathrm{CCl}_{4}$ fractions than in the corresponding control sample (Table I).

\section{Statistical significance}

Significance was determined by analysis of variance and comparison of means by the Bonferroni-Scheffe method [25]. Significance was assumed for $P<0.05$.

\section{RESULTS}

Purity of the membrane fractions was assessed by determination of marker enzyme activities and did not differ markedly from control at any time after $\mathrm{CCl}_{4} \mathrm{ex}-$ posure except for an increased inner mitochondrial membrane contamination of the outer membrane fraction $40 \mathrm{~h}$ after $\mathrm{CCl}_{4}$. Based on the specific activity of cytchrome $c$ oxidase in the outer membrane fraction, inner membrane contamination of outer membrane protein increased from 18 to $46 \%$ at $40 \mathrm{~h}$. The effect of this contamination was to dilute the extent of changes observed in the outer membrane.

Incorporation of $\left[{ }^{3} \mathrm{H}\right]$ ethanolamine at $40 \mathrm{~h}$ into outer membrane and inner membrane PE was $<30$ and $55 \%$ of control, respectively. Microsomal PE-specific radioactivity was $67 \%$ of control levels at this tine (Table II). The specific radiuactivity of PE returned to control levels in the microsomal and inner membrane fractions by $65 \mathrm{~h}$ after $\mathrm{CCl}_{4}$, but the specific radioactivity of $\mathrm{PE}$ in the outer membrane fraction was twice that observed in controls. The rate of PE synthesis in all three 


\section{TABI F. II}

$\left[{ }^{3} \mathrm{H}\right]$ ETHANOLAMINE HCI INCORPORATION IN MICROSOMAL AND MITOCHONDRIAL PHOSPHATIDYLCHOLINE (PC) AND PHOSPHATIDYLETHANOLAMINE (PE) FOLLOWING

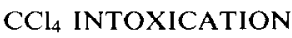

Phospholipids were extracted from inner and outer mitochondrial and microsomal membrane fractions as described in METHODS. Incorporation is expressed as CPM $/ \mu \mathrm{g}$ phospholipid-phosphorus. Numbers in parentheses are percent control. Fractions were prepared from 10 rats at each time point.

\begin{tabular}{|c|c|c|c|c|}
\hline \multirow[t]{2}{*}{ Phospholipid } & \multirow[t]{2}{*}{ Control } & \multicolumn{3}{|c|}{ Time after $\mathrm{CCl}_{4}(\mathrm{~h})$} \\
\hline & & 40 & 65 & 165 \\
\hline \multicolumn{5}{|c|}{ Outer mitochondria } \\
\hline $\mathrm{PC}$ & 45.5 & $14.0(31)$ & $65.3(144)$ & $50.3(111)$ \\
\hline PE & 337.5 & $97.8(29)$ & $683.1(202)$ & $384.1(114)$ \\
\hline \multicolumn{5}{|c|}{ Inner mitochondria } \\
\hline $\mathrm{PC}$ & 32.7 & $13.4(39)$ & $59.5(182)$ & $42.3(127)$ \\
\hline $\mathrm{PE}$ & 288.3 & $156.1(54)$ & $268.6(93)$ & $217.1(75)$ \\
\hline \multicolumn{5}{|l|}{ Microsomes } \\
\hline $\mathrm{PC}$ & 59.9 & $33.1(55)$ & $73.5(123)$ & $58.0(97)$ \\
\hline $\mathrm{PE}$ & 722.2 & $483.0(67)$ & $717.1(99)$ & $713.0(99)$ \\
\hline
\end{tabular}

\section{TABLE III}

EFFECT OF $\mathrm{CCl}_{4}$ INTOXICATION ON THE IN VITRO METHYLTRANSFERASE ACTIVITY OF THE MICROSOMAL MEMBRANE FRACTION FROM RAT HEPATOCYTE

Microsomal membrane fractions were prepared from individual livers. Activity is expressed as CPM of $\left.{ }^{3} \mathrm{H}\right] S$-adenosylmethionine incorporated per $\mathrm{mg}$ protein per $15 \mathrm{~min}$ incubation at $37^{\circ} \mathrm{C}$. The synthesis of PC from PE (PE $\rightarrow$ PC) and from phosphatidyldimethylethanolamine (PD $\rightarrow$ PC) was measured (see METHODS).

\begin{tabular}{llc}
\hline Time after $\mathrm{CCl}_{4}(\mathrm{~h})$ & $\mathrm{PE} \rightarrow \mathrm{PC}$ & $\mathrm{PD} \rightarrow \mathrm{PC}$ \\
\hline Control & $412.8 \pm 47.3(8)$ & $115.1 \pm 10.9(8)$ \\
10 & $192.3 \pm 29.9(4)^{\mathrm{a}}$ & $50.6 \pm 18.4(5)^{\mathrm{b}}$ \\
20 & $284.4 \pm 43.4(8)$ & $60.6 \pm 9.5(7)^{\mathrm{b}}$ \\
40 & $226.3 \pm 33.6(4)$ & $57.3 \pm 16.1(4)^{\mathrm{a}}$ \\
65 & $212.5 \pm 44.9(2)$ & $61.5 \pm 9.6(6)^{\mathrm{b}}$ \\
\hline
\end{tabular}

Significance (determined by one-way analysis of variance and Bonferroni-Scheffe analysis of means): ${ }^{\mathrm{a}} P<0.05 ;{ }^{\mathrm{b}} P<0.01$.

membrane fractions at $165 \mathrm{~h}$ was essentially that of control values.

The pattern of changes of $\mathrm{PC}$ synthesis $40 \mathrm{~h}$ after $\mathrm{CCl}_{4}$ was similar to that of $\mathrm{PE}$. Incorporation of $\left[{ }^{3} \mathrm{H}\right]$ ethanolamine into $\mathrm{PC}$ in the microsomal membrane was $55 \%$ of control, while the labelling of $P\left(C^{\prime}\right.$ in both mitochondrial membranes was depressed $30-41 \%$ at this time. All three fractions had elevated rates of labelling $65 \mathrm{~h}$ after $\mathrm{CCl}_{4}$. The labelling of $\mathrm{PC}$ in mitochondrial membranes remained above control values at $165 \mathrm{~h}$. 
Methyltransferase activity was measured in microsomes isolated from $\mathrm{CCl}_{4}$-dosed rats (Table III). As expected, the 3-step methylation pathway (PE to PC) incoroporated roughly 3 times the radioactivity as did the final step (PD to PC). The specific activity of the 3 -step methylation pathway of $P E$ to $P C$ in vitro was depressed at $10 \mathrm{~h}$ after in vivo exposure to $\mathrm{CCl}_{4}$ (Table III). A significant decline in activity was found at all times when the methylation of PD was assayed. In both assays, the greatest depression of activity was found at the earliest time examined, $10 \mathrm{~h}$ after $\mathrm{CCl}_{4}$ exposure. Methyltransferase activity was not detected in the mitochondrial fraction from either control or $\mathrm{CCl}_{4}$-exposed rat livers.

\section{DISCUSSION}

Reduced levels of newly synthesized PE and PC occur in the hepatic microsomal and inner and outer mitochondrial membrane fractions $40 \mathrm{~h}$ after $\mathrm{CCl}_{4}$, the same time that functional and compositional alterations are found in these membranes. Rates of oxidative phosphorylation are severely inhibited [1,2] and evidence of outer-membrane damage is present [13]. Similar studies reported that cytochrome P-450 concentrations [11], glucose-6-phosphatase activity [10,11] and Ca-ATPase activity [12] are depressed in microsomal fractions from rats after $\mathrm{CCl}_{4}$ exposure. The depressed rates of synthesis of $\mathrm{PE}$ and $\mathrm{PC}$ are consistent with previously described changes of phospholipid content in microsomal and mitochondrial membranes [5] and suggests that the altered phospholipid composition of these membranes could be attributed, at least in part, to impaired function of the enzymes involved in phospholipid synthesis. At $65 \mathrm{~h}$ after $\mathrm{CCl}_{4}$, when mitochondrial function and phospholipid composition are partially restored to normal $[1,5]$ the specific activity of PC was greater than that of control in all 3 of the membrane fractions and that of PE was increased in the outer-membrane fraction (Table II). This is consistent with an accelerated rate of synthesis of membrane components associated with the restoration of mitochondrial function at $65 \mathrm{~h}$.

The enzymes involved in the methylation of PE to PC were significantly depressed $10 \mathrm{~h}$ after $\mathrm{CCl}_{4}$. The depressed activity of the PD methyltransferase pathway at 65 $h$ appears to contradict the increased amount of labelled PC present in the microsomes at this time as detected by the in vivo experiment. Apparently, the in vitro methyltransferase activities were sufficient to fulfill the in vivo demands of this pathway.

The critical processes by which $\mathrm{CCl}_{4}$ produces hepatocyte death are not resolved [26]. However, the association between proper membrane function and lipid composition is well recognized $[4,27]$. These results suggest that the inhibition of phospholipid synthesis may be important in the development of membrane damage and that recovery of synthesis is concomitant with the resolution of damage. 


\section{ACKNOWLEDGEMENT}

This work was supported by PHS grant ES01919 to M.J.B., and NIEHS T32ES07062. The authors thank Dr. Felix de la Iglesia and Dr. Barry Peters for their helpful comments during the course of this work, and Ms. Katherine Milliken for her aid in the preparation of this manuscript.

\section{REFERENCES}

1 M.J. Brabec, R.H. Gray and I.A. Bernstein, Restoration of hepatic mitochondria during the recovery from $\mathrm{CCl}_{4}$ intoxication, Biochem. Pharmacol., 23 (1974) 3227-3238.

2 E.S. Reynolds, R.E. Thiers and B.L. Vallee, Mitochondrial function and metal content in carbon tetrachloride poisoning, J. Biol. Chem., 237, (1962) 3546-3551.

3 M. Sugano, S. Cho, K. Imaizumi and M. Wada, Hepatotoxicity and lipid metabolism, III. Changes in phosphatidylcholine and phosphatidylethanolamine during hepatic injury caused by $\mathrm{CCl}_{4}$, Biochem. Pharmacol., 19 (1970) 2325-2333.

4 M.S. Ilyas, F.A. de la Iglesia and G. Feuer, The effect of phenobarbital and $\mathrm{CCl}_{4}$ on fatty acid content and composition of phospholipids from the endoplasmic reticulum of rat liver, Toxicol. Appl. Pharmacol., 44 (1978) 491-504.

5 A.M. Wisner-Gebhart, R. Head and M.J. Brabec, The effect of $\mathrm{CCl}_{4}$ exposure on mitochondrial membrane phospholipids, Toxicologist, 2 (1982) 33 (Abst.).

6 E.A. Dennis and E.P. Kennedy, Intracellular sites of lipid synthesis and the biogenesis of mitochondria, J. Lipid Res., 13 (1972) 263-267.

7 F.B. Jungalwala and R.M.C. Dawson, The origin of mitochondrial phosphatidylcholine within the liver cell, Eur. J. Biochem., 12 (1970) 399-402.

8 L. Stuhne-Sekalec and N.Z. Stanacev, On the mechanism of spontaneous transfer of lipids from isolated microsomal to mitochondrial membranes, Can. J. Biochem., 60 (1982) 137-143.

9 K.W.A. Wirtz and D.B. Zilversmit, Exchange of phospholipids between liver mitochondria and microsomes in vitro, J. Biol. Chem., 243 (1968) 3596-3602.

10 M.J. Brabec, J.B. Owens, M. Kenel, D. Sorscher and H.H. Cornish, Modification of methanol potentiation of $\mathrm{CCl}_{4}$ toxicity in rats by chloramphenicol, Drug Chem. Toxicol., 5 (1982) 143-154.

11 E.A. Glende. Carbon tetrachloride-induced protection against carbon tetrachloride toxicity: role of the liver microsomal drug metabolizing system, Biochem. Pharmacol., 21 (1972) 1697-1702.

12 L. Moore, G. Davenport and E. Landon, Calcium uptake of a rat liver microsomal subcellular fraction in response to in vivo administration of $\mathrm{CCl}_{4}, \mathrm{~J}$. Biol. Chem., 25 (1976) 1197-1204.

13 M.J. Brabec, T. Pastoor, P. Drenchko, R. Head and I.A. Bernstein, Loss of sulfite oxidase activity and outer membrane damage in rat hepatic mitochondria during $\mathrm{CCl}_{4}$ poisoning, Biochem. Biophys. Res. Commun., 76 (1977) 189-195.

14 E.D. Dolci and M.J. Brabec, Antagonism by chloramphenicol of $\mathrm{CCl}_{4}$ hepatotoxicity, Exp. Mol. Pathol., 28 (1978) 96-106.

15 G.L. Decker and J.W. Greenawalt, Ultrastructural and biochemical studies of mitoplasts and outer membranes derived from French-pressed mitochondria. J. Ultrastruct. Res., 59 (1977), 44-56.

16 A.G. Gornall, C.J. Bardawill and M.M. David, Determination of serum proteins by means of the biuret reaction, J. Biol. Chem., 177 (1949) 751-766.

17 C. Tabor, H. Tabor and S. Rnsenthal, Purification of amine oxidase from beef plasma, J. Biol. Chem., 208 (1954) 645-661.

18 D. Wharton and A. Tzagoloff, Methods Enzymol., 10 (1967) 245.

$19 \mathrm{C}$. Williams and H. Kamin, Microsomal triphosphopyridine nucleotide-cytochrome $c$ reductase of liver, J. Biol. Chem., 237 (1962) 587-595. 
20 D.R. Hoffman and W.E. Cornatzer, Microsomal phosphatidylethanolamine methyltransferase: Some physical and kinetic properties, Lipids 16 (1981) 533-540.

$21 \mathrm{~J}$. Bremer and D. Greenberg, Methyl transferring enzyme system of microsomes in the biosynthesis of lecithin (phosphatidylcholine) Biochim. Biophys. Acta, 46 (1961) 205-216.

22 J. Folch, M. Lee and G.H.S. Stanley, A simple method for the isolation and purification of total lipids from animal tissues, J. Biol. Chem., 226 (1957) 497-509.

23 Y. Matsuzawa and K. Hosteller, Inhibition of lysosomal phospholipase A and phospholipase $\mathrm{C}$ by chloroquine and 4,4' -bis(diethylaminoethoxy) $\alpha, \beta$-diethyl-diphenylethane, J. Biol. Chem., 255 (1980) $5190-5194$.

24 P. Kankare and D. Suovaneim, A simple method for determination of phosphate from thin-layer chromatographic plates, J. Chromatog., 62 (1971) $485-486$.

25 R.G. Miller, Simultaneous Statistical Inference, McGraw-Hill, New York, 1966.

26 R.O. Recknagel, Carbon tetrachloride: status quo and future prospects, Trends Pharmacol. Sci., 4 (1983) 129-131.

27 E.A. Glende, On the mechanism of $\mathrm{CCl}_{4}$ toxicity - Coincidence of loss of drug metabolizing activity with peroxidation of microsomal lipid, Biochem. Pharmacol,, 21 (1972) 2131-2138. 